\title{
Cutting Forces, Chips Formation and Surface Roughness in Rock Cutting Using Negative Rake Angle
}

\author{
Yuni Hermawan ${ }^{1}$, Rudy Soenoko 2, Yudy Surya Irawan ${ }^{2}$, Sofyan Arief Setyabudi 2 \\ ${ }^{1}$ Mechanical Engineering Department, Faculty of Engineering, University of Jember, Jl. Kalimantan No 37, Jember \\ 68121, Indonesia, E-mail: yunikaka@unej.ac.id \\ ${ }^{2}$ Mechanical Engineering Department, Faculty of Engineering, Brawijaya University, Jl. MT Haryono No. 169, \\ Malang 65145, Indonesia, E-mail: rudysoen@ub.ac.id, yudysir@ub.ac.id, sasbudi@ub.ac.id
}

This research pertains to rock cutting used negative rake angle. The parameters used are negative rake angles of $0^{\circ},-5^{\circ},-10^{\circ},-15^{\circ},-25^{\circ},-30^{\circ}$, and $-40^{\circ}$. Negative rake angle is known to play an important role in rock machining. Negative rake angle produces more chips powder in front of the tool surface. The interaction between these particles affects the radial force that suppresses the rock surface. A large radial force generates hydrostatic pressure around the tooltip. According to the findings of this research, negative rake angle $-25^{\circ}$ leads to the largest radial force and smallest surface roughness for $15.17 \mathrm{~N}$ and $1.21 \mu \mathrm{m}$, respectively with smooth and uniform chips. The rock surface and the resulting chips powder was observed by scanning electron microscope (SEM) in order to prove the effect of hydrostatic pressure working on the tooltip. Meanwhile the hydrostatic pressure changed the brittle cutting mode into a brittleductile cutting mode.

Keywords: rock cutting, negative rake angle, cutting force, and surface roughness.

\section{Introduction}

The rocks are classified as brittle material [1,2] found in copious amounts. It is one of the most nonmetallic minerals on earth. Rocks are endowed with certain properties: not absorbing heat, hard and brittle. Rock marble is widely used for addressing the needs of building walls, floors, and various kinds of rock crafts. Examples: flower vases, ornaments, bath-ups, body of medals, statues, and onyx crafts. In order to make products from rock materials, machining is usually undertaken, which comprises of the following: turning, drilling, milling, and sawing. The main purpose of machining is to produce smooth surface quality, which is also the biggest challenge in brittle material machining. Damage-Free machining can only be achieved by altering the brittle cutting mode to ductile cutting mode [1, 3-5]. Some methods are used to achieve the ductile cutting modes, namely: machining with a very small cutting depth (micron) so that the depth of cut is below the critical depth of the material, something that can only be done in micromachining [6]. The second method exerts pressure on the surface of the workpiece to be machined, with a view to form hydrostatic pressure around the cutting tool.

One way to increase the pressure in front of the cutting tool is to make the negative rake angle; this is in contrast with ductile material machining that uses a positive rake angle. Rake angle is an angle formed between the surface of a tool with a line perpendicular to the surface of the workpiece [7]. This negative rake angle produces a radial force that presses the workpiece, which then creates a significant amount of hydrostatic pressure in front of the cutting chisel surface. Hydrostatic pressure has altered the cutting mode from brittle cutting mode to ductile cutting mode $[1,3]$. Several studies have been conducted on the use of negative rake angles for cutting, including Che et al. [4], who mentioned that the mechanism of chips formation with the presence of a tangential force $\left(F_{c}\right)$ and radial force $\left(F_{\mathrm{p}}\right)$ are exfoliated from the parent metal through the sliding plane. Brittle cutting mode to ductile cutting mode is strongly predicated on the pressure around the cutting tool. Correspondingly, Sabri Ozturk stated that rake angle plays an important role in the cutting mechanism [7].

Research on cutting force with other methods was carried out by: Che D [2], who investigated the following: Indiana face turning with diamond chisels with rake angle $\gamma=25^{\circ}$, feeding motion $0.4 \mathrm{~mm} / \mathrm{rev}$ and spindle rotation $300 \mathrm{rpm}$. The result: There is a linear relationship between the depth of the cut with the tangential force $\left(F_{c}\right)$ and radial force $\left(F_{p}\right)$ if other parameters are made constant. However, there is a non-linear relationship if the feeding motion and spindle rotation are varied. Analogously, Che et al. [5] conducted a study of cutting force response in Indiana rock face turning with polycrystalline diamond compact (PDC) tool, $0.8 \mathrm{~mm} / \mathrm{rev}$ feeding motion and rake angle $\gamma=$ $10^{\circ}, 15^{\circ}$, and $25^{\circ}$. They found that as the tool starts 
cutting, the force component increases rapidly (starting phase) before entering the stable phase until it approaches the flashlight of the workpiece. After entering the center line of the workpiece, the force component increased quickly (unstable phase) until all materials were removed.

Kaitkay and Lei [1] conducted a study on the cutting force of Chartage marble stone turning on hydrostatic pressure condition, diamond tool and rake angle $\gamma=-5^{\circ}$ to $-25^{\circ}$, feeding $0.8 \mathrm{~mm} / \mathrm{rev}$ and cutting speed of $1 \mathrm{~m} / \mathrm{s}$. They observed that the cutting force increased after increasing the negative rake angle and hydrostatic pressure, whereas the application of external hydrostatic pressure has kept the chips formation mechanism. Wilson [8] meanwhile conducted a study of cutting force on cutting Granite stones with a ReedPrentice lathe with a rake angle of $-10^{\circ}$. The force measurements were carried out with a 3-axial strain gage dynamometer with a view to determine three components of the cutting force. The result: the value of axial force $\left(F_{\mathrm{f}}\right)$ and tangential force $\left(F_{\mathrm{c}}\right)$ is much smaller than the radial force $\left(F_{\mathrm{p}}\right)$. The largest radial force is $1200 \mathrm{~N}$, whereas the largest axial force and tangential force of $100 \mathrm{~N}$ was measured at $240 \mathrm{sec}-$ onds.

Che D [9] posited that the cutting force observed in the milling process of rock material with type: Indiana limestone, Austin chalk and Barera sandstone with rake angle $10^{\circ}, 15^{\circ}, 20^{\circ}, 25^{\circ}$, and $30^{\circ}$ while the measured component forces are tangential force $\left(F_{c}\right)$, radial force $\left(F_{\mathrm{p}}\right)$ and axial force $\left(F_{\mathrm{f}}\right)$. The result showed that the ratio between tangential force and radial force has a constant value for the same rake angle without being affected by the cutting speed or depth of the cut. FC Appl conducted a study of cutting cylinder granite stones through the polycrystalline diamond compact (PDC) tools [10]. The cutting process was found to be varied: cutting speed, feeding, and depth of cut. Cutting conditions are undertaken with coolant, and without coolant, whereas parameters observed are cutting force, temperature, and tool wear. The value of cutting force with conditions using coolant is as follows: radial force $589 \mathrm{~N}$, axial force $196 \mathrm{~N}$ and tangential force 222 N. Verhoef [3], conducted experiments on 3-axial rock testing machines. The research focused on the change of brittle cutting mode to the ductile cutting mode by conditioning the pressure on the tooltips along with the workpiece surface. The result showed the brittle-ductile cutting mode plays an important role because the ductile cutting mode affects the area of the crushed zone. In addition, the ductile cutting area must be wider, and the brittle cutting area needs to be less.

Nishimatsu [11] investigated the cutting force on the rock with a positive rake angle. This study revealed that rake angles are known to play an important role in cutting rocks, because they are required to make crushed zones around cutting tools such as built-up edges on metal cuts that occur periodically. Saurav Goel [6] researched the use of cutting ceramics on precision lathes (micro-machining) with diamond tools, rake angle $\gamma=-25^{\circ}$ and spindle speed $382 \mathrm{rpm}$. The result showed the radial force during the cutting process is a requirement that is required to carry out the ductile cutting conditions. Meanwhile Checkina [12] conducted a modeling study of rocks cutting with rake angle $15^{\circ}$ on tool wear and elastic deformation crushing; the result of the average cutting force horizontal direction $P_{\mathrm{g}}$ and vertical direction $P_{\mathrm{v}}$ was shown to affect the area of crushed deformation and tool wear. Hough [13] carried out an experimental study of the effect of rake angle on the performance of diamond tools. The rake angles were found to be varied: $7^{\circ}, 15^{\circ}$, $20^{\circ}$ and $25^{\circ}$, spindle speeds of 500 and $750 \mathrm{rpm}$, black marble workpiece. The results showed rake angle of $20^{\circ}$, which produces maximum pressure. The optimum pressure and torque rates are obtained from the rake angles $7^{\circ}$ and $20^{\circ}$. Hamade [14] conducted a study of cutting forces in the milling process with basalt rock material with negative rake angles: $-5^{\circ},-10^{\circ},-15^{\circ}$, and $-25^{\circ}$. The cutting force measurements are undertaken with a Kistler dynamometer. The result showed that a negative rake angle has a very significant effect on the magnitude of radial force; the largest radial force in the milling process is $1120 \mathrm{~N}$.

Negative rake angle plays an important role in shaping the brittle machining material. Negative rake angle has positioned a significant amount of hydrostatic pressure in front of the tool and prevents the cracking initiation on the workpiece surface, so that it changed the brittle cutting mode into ductile cutting mode [1, 3-5]. Meanwhile the findings of the studies $[2,5,9,11-13]$ examined cutting forces in rock materials using a positive rake angle. They only discussed cutting forces with variations in the parameters of cutting speed, feeding, and depth of cut. They did not discuss the phenomenon of radial force, hydrostatic pressure, and rock machining that is known to produce the smallest surface roughness. Then, the results of the study $[1,3,8,10,14]$ used negative angle, and only a few studies examined the effect of radial force on hydrostatic pressure, which resulted in ductile cutting mode. However, this particular study only observed until $-25^{\circ}$ rake angle. Meanwhile the researchers are yet to discuss the effects of negative rake angles on surface quality. For this reason in this study, the authors conducted the study: "Analysis of cutting forces, chips formation and surface roughness in rock cutting using negative rake angle." This study focused on variations in negative rake angles ranging from $0^{\circ}$ to $-40^{\circ}$ even as the other parameters were made constant. The results of this rock cutting study can be used in the industry of rock walls and floors, onyx objects, sculptures, ornaments, mining, gas, and oil drilling. 


\section{MATERIALS AND METHODS}

Marble rock was taken from natural marble in the mountains of Tulungagung - Indonesia; it is a type of cream-colored marble with chemical composition, as shown in Tab. 1.

Tab. 1 Chemical composition marble rock (\%) of weight.

\begin{tabular}{|c|c|c|c|c|c|c|}
\hline $\mathrm{Cu}$ & $\mathrm{Co}$ & $\mathrm{Er}$ & $\mathrm{Fe}$ & $\mathrm{Lu}$ & Mo & $\mathrm{Ca}$ \\
\hline 0.041 & 0.082 & 0.1 & 0.12 & 0.15 & 0.27 & 99.23 \\
\hline
\end{tabular}

Rock cutting was undertaken on the "Yamazaki" semi-automatic lathe, a workpiece with a diameter of $40 \mathrm{~mm}$ and a length of $200 \mathrm{~mm}$. The cutting was done without coolant with parameters: tool orthogonal rake angles of $0^{\circ},-5^{\circ},-10^{\circ},-15^{\circ},-25^{\circ},-30^{\circ}$, and $-40^{\circ}$. Constant parameters included spindle speed, feeding, depth of cut for $350 \mathrm{rpm}, 0.135 \mathrm{~mm} / \mathrm{rev}, 1 \mathrm{~mm}$, respectively. The tools used included the "Widia YG6"

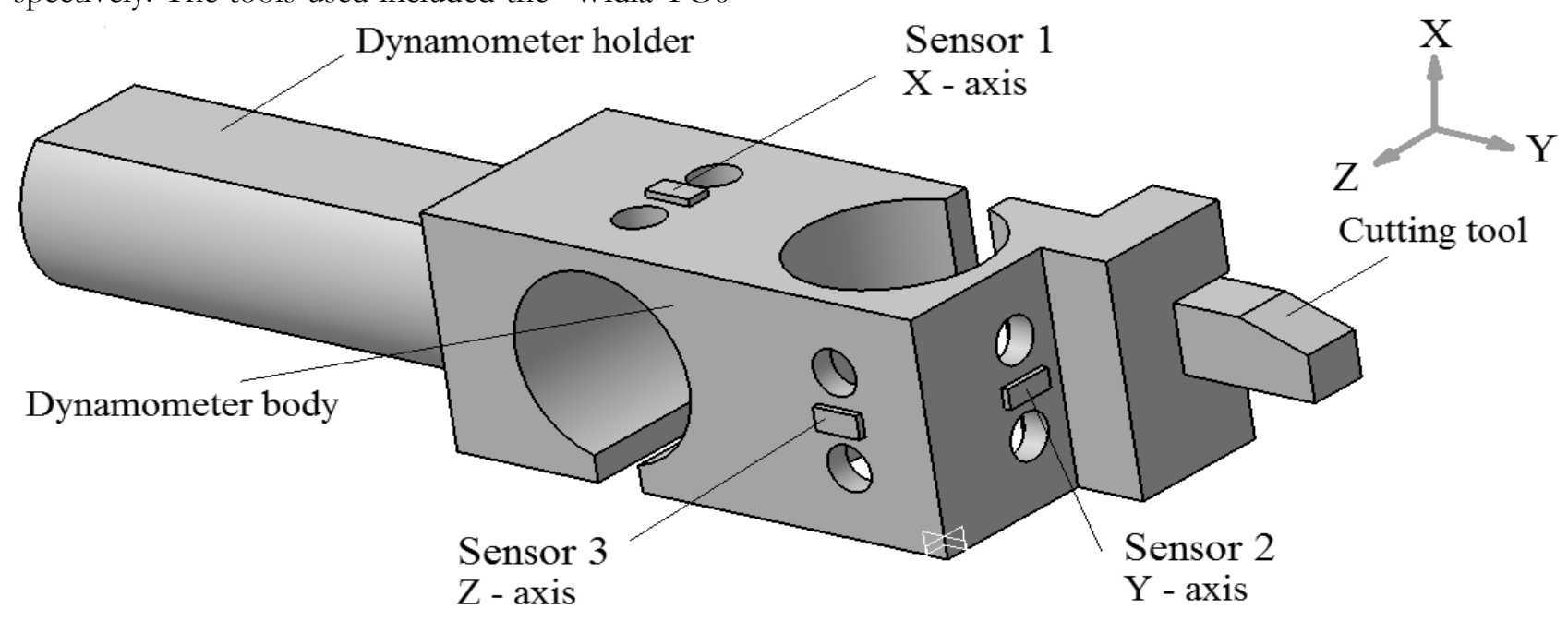

Fig. 1 Design of dynamometer with 3-axial strain gage for marble rock cutting

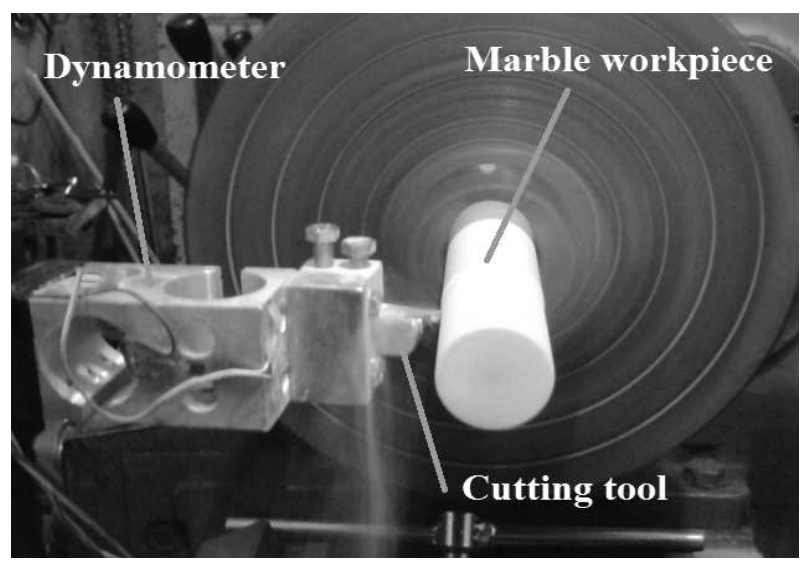

Fig. 2 The tri-axial strain gage dynamometer during the machining process.

In the turning process, there are three components of force, namely the tangential force $F_{c}$, the force in the direction of the $\mathrm{x}$-axis, the radial force $F_{\mathrm{p}}$ in the direction of the $Y$-axis, and the axial force $F_{\mathrm{f}}$ in the direction of the $Z$ axis. The value of the force compo- tungsten carbide insert.

\section{Cutting Force Measurement}

The measurement cutting force utilized the tri-axial dynamometer with strain gage sensor $120 \Omega$. Strain gage sensor was installed on the dynamometer in accordance to the direction of force; strain gage 1 was installed to respond the tangential force $\left(F_{c}\right)$ in direction $\mathrm{X}$, whereas strain gage 2 was installed in response to the radial force $\left(F_{\mathrm{p}}\right)$ in the $\mathrm{Y}$ direction. Strain gage 3 was installed in response to the axial force $\left(F_{\mathrm{f}}\right)$ in the $\mathrm{Z}$ direction. The dynamometer body was then connected to a dynamometer holder bar before being clamped into the toolpost. The dynamometer holder was used as a pedestal dynamometer. The tri-axial dynamometer design is illustrated in Fig. 1. 


\section{Surface Roughness Measurement}

Surface roughness was measured through the use of a Surface Roughness Tester "TR-220" with the maximum step length of $8 \mathrm{~mm}$. This study made use of arithmetic roughness ( $\mathrm{Ra}$ ). The workpiece was placed on a flat table, subsequent to which the measuring instrument was placed on the test object right at the measurement position. The surface roughness tester was calculated automatically and displayed on the screen. Measurement of surface roughness was carried out in the direction of the elongation of the workpiece: this measurement process takes three positions of the measurement point, namely at the position of the workpiece (position 1), the center position of the workpiece (position 2), and the position closest to the chuck (position 3). Each position was carried out four times in accordance with the quadrant.

\section{Results and Discussion}

In the cutting process of marble rock, the measure- ment of cutting force was undertaken with a dynamometer of the 3-axial gage strain. Gage strains are placed in three measurement positions, $X$ direction to measure tangential force, $Y$ direction to measure radial force, and $Z$ direction to measure axial force. Fig. 3 illustrates the track of the rock cutting process: when the turning starts getting turned on, the tool move from point 1 to the workpiece without feeding the free phase releases this movement to point 2 . The tools then move towards the end of the workpiece point 2 before starting to feed, so that the force component began increasing rapidly to point 3 ; this phase is referred to as the unstable phase which does not lost before it reaches a relatively stable phase. In a stable phase, it lasts for a long time, starting at point 3 , then reaching the middle of cutting point 4 and finally ending at point 5 nearing the lathe chuck. After the tool approached the lathe chuck, the cutting tools were extracted and neutralized so that all the components of the force were dropped rapidly towards point 6 (end point) and the end of the process of rock cutting towards point 7 , also referred to as the free phase.
Location of tool
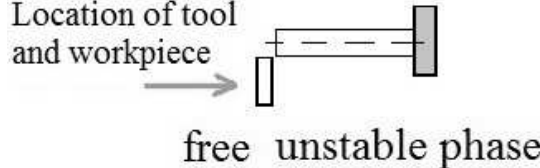

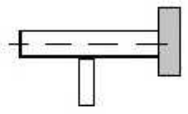

stable phase

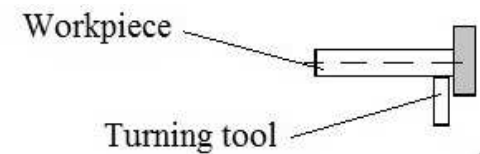

free

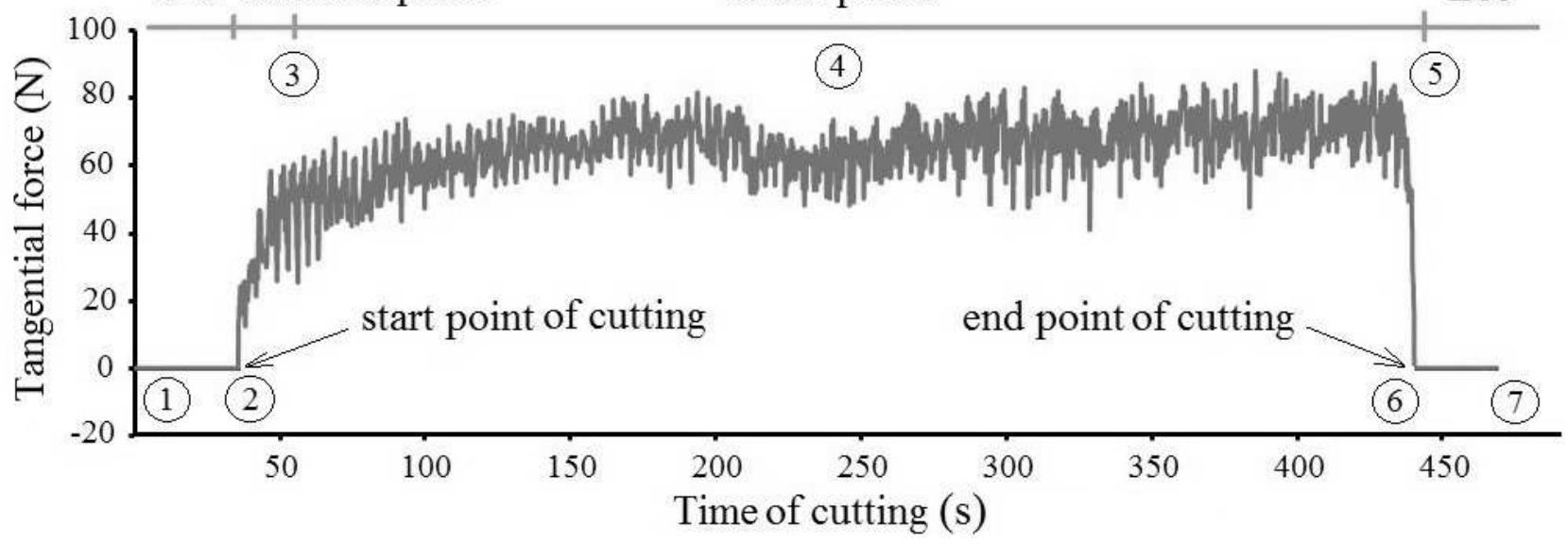

Fig. 3 Experimental data of the tangential force $\left(F_{c}\right)$ response to time on the rake angle $-15^{\circ}$.

The response of the cutting force to the negative angle rake is illustrated in Fig. 4. The average tangential force $\left(F_{c}\right)$ ranges from $60 \mathrm{~N}$ the same almost for all negative rake angles. The value of the tangential force is always greater than the axial force and the radial force. The magnitude of the axial force is greater than the radial force at almost all the negative rake angle, but the axial force is smaller than the radial force at the rake angle $-25^{\circ}$. The occurrence of force fluctuations shows the phenomenon of brittle materials and non-homogeneous structures in marble rock materials $[1,5]$. The mechanism of chips formation follows the crushing and shearing mechanism $[1,3,9,11,15]$. The force was increased at the beginning of the crack formation and decreased suddenly when the crack has spread [9]. Differences were found in the force fluctuations at the beginning of cutting and the end of rock cutting due to differences in deflection of a workpiece. The marble rock tip without tailstock was supported, and the other end of marble rock was supported by spindle chuck. The force fluctuations on the negative rake angle of $-25^{\circ}$ was found to be more stable; in addition, the difference between the initial cutting and the end of the cutting is found to be relatively small. This occurs because the cutting process is more dominant on the crushing mechanism rather than shearing mechanism. The results of cutting forces measurement on marble rock cutting are shown in Fig. 4. 

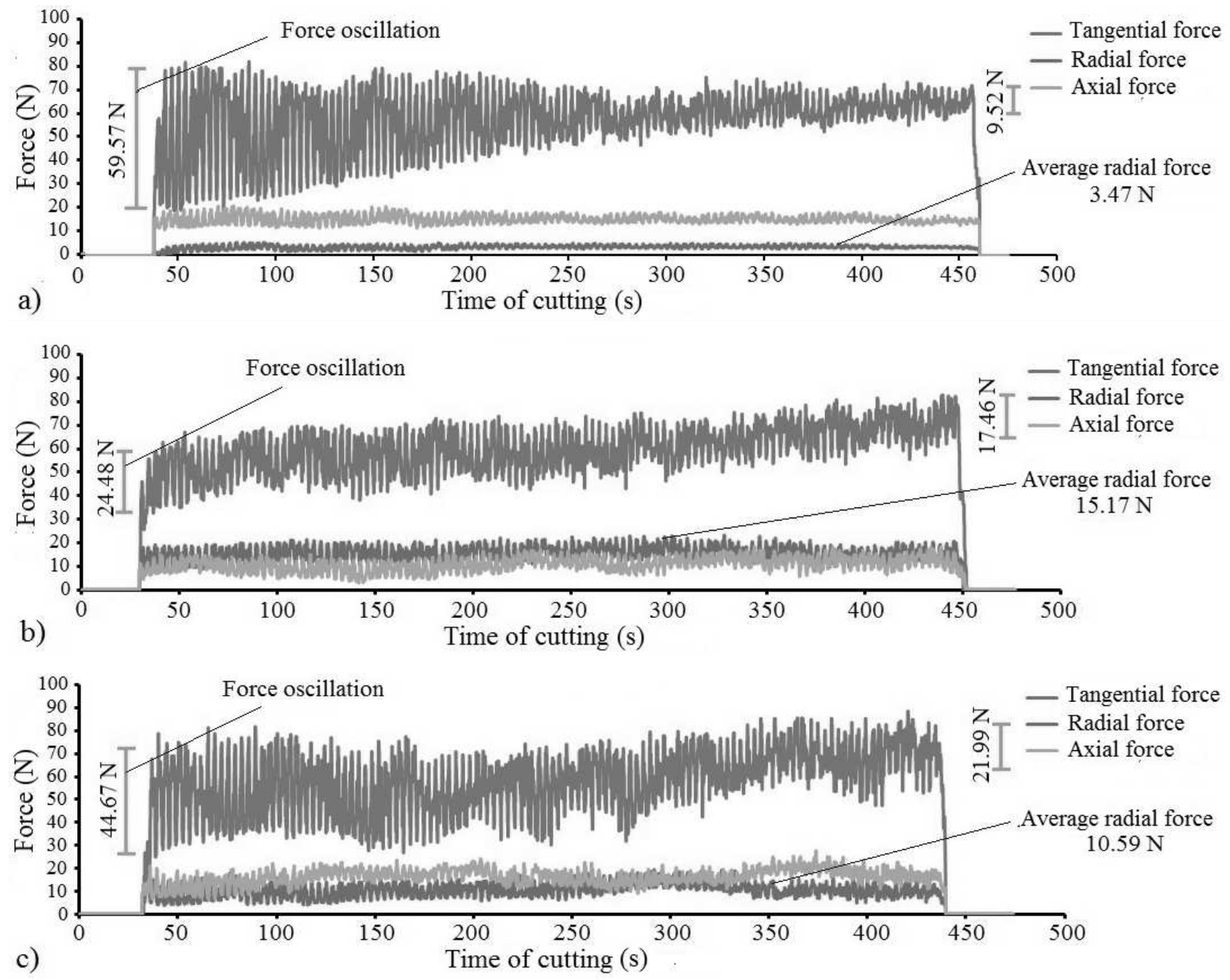

Fig. 4 The cutting forces response, a) rake angle $0^{\circ}$, b) rake angle $-25^{\circ}$ and c) rake angle $-40^{\circ}$

The magnitude of the tangential force component was identified by calculating the average force that occurs during the cutting process in the stable phase [5]. It was seen that the cutting process occurred in the period from 0 to 500 seconds. At the starting phase, the force component data was not included in the calculation because the magnitude of the force fluctuations remained high. Fig. 5 shows that the tangential force $\left(F_{c}\right)$ has an average that is almost the same for all negative rake angles: \pm 60 Newton. The magnitude of the axial force $\left(F_{\mathrm{f}}\right)$ and radial force $\left(F_{\mathrm{p}}\right)$ are much smaller than the tangential force $\left(F_{c}\right)$. On the rake angle $-25^{\circ}$ the maximum radial force $\left(F_{\mathrm{p}}\right)$ was found to be $15.17 \mathrm{~N}$, and the minimum axial force $\left(F_{\mathrm{f}}\right)$ is 10.85 $\mathrm{N}$, in comparison to other rake angles. The phenomenon of forces fluctuation in rock cutting was caused by characteristics of the brittle fracture of rocks and non-homogeneous structures [1, 4]. In the rock cutting cycle, the force is increased at the beginning of the tool's penetration to the workpiece until its peak at the beginning of the crack formation. The force decreased suddenly when the crack began spread [11].
This caused the oscillation of cutting force in the cutting rock. The contact between a chips particle in front of the tooltip was found to increase the radial force. In the rock cutting, the radial force is vital for the purpose of producing a large amount of hydrostatic pressure $[1,3,7,16]$. The hydrostatic pressure was generated on a crushed zone in the rock cutting mechanism. The large radial force influences the crushing mechanism. Meanwhile, the cutting mechanism was dominantly shearing for the brittle cutting mode. The effect of the crushing and shearing mechanism in the rock cutting was seen in the results of surface roughness as well as the shape of the chips [9].

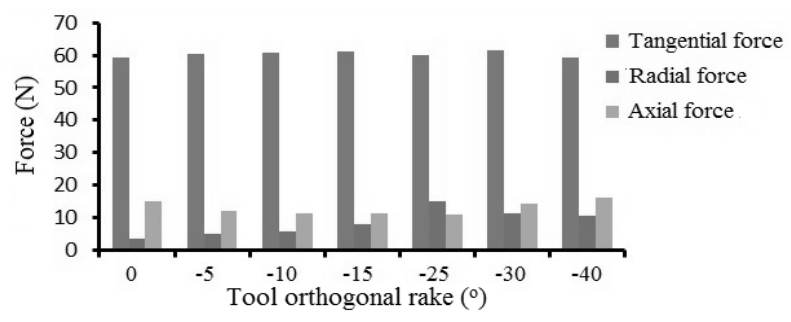

Fig. 5 The average force component with the function of the tool orthogonal rake angle. 
The chips formation in the powder form was found to be beneficial in rock cutting. In this condition, the chips could still continuously, erode, and join along with the moving tool. The presence of chips helps reduce the stress concentration caused by the force of the tool that contacts with the workpiece surface. In the rock cutting with rake angle $0^{\circ}$, the resulting chips powders are scattered to generate a small radial force. The cutting process with a sharp angle forms a stress concentration on the tooltip, and the cutting mode that occurs in the brittle cutting mode. In the brittle cutting mode, shearing and crack mechanism occurred in the rock cutting. In the rock cutting with a rake angle of $-25^{\circ}$ the crushing mechanism was found to be dominant. The resulting chips powders accumulated in front of the tool and are continuously crushed in the cutting process. The interaction between the chips particles generated a radial force. $[1,3,9]$.

\section{The Observed Chips Formation}

The material and machining conditions greatly influence the shape of the chips. The chips results of the machining process can be used as an indicator of machining quality. The small chips can be refer to better surface quality $[17,18,19]$. The machining of fibreboards and polystyrene was producing chips powder.
The chips will be divided into very small chips and large chips with microparticles shape. The observations of chips are done using scanning electron microscope [20]. In this research, the material used is marble rock which produces chips powder. Tab. 2 shows the shape of chips the results of the cutting process marble rock. The rake angle of $0^{\circ}$ results in the size of a non-uniform chip consisting of four types of chips, namely: very big chips, big chips, small size chips, and chips powders. The big size of chips is very dominant. This is because the process of chips formation occurs in the shearing process is more dominant than the crushing process. The process of cutting marble rock with a rake angle of $-25^{\circ}$ produces chips powder, which is very dominant. As per this observation, it was not found the big chips. It was attributed to the chip formation caused by the dominantly crushing process. The cutting process with a negative rake angle $-40^{\circ}$ led to the creation of big chips and small chips. The chips consist of: very big chips, big chips, small chips, and chips powder. In this observation, a very big chip was found. However, at the rake angle of $-40^{\circ}$, the size of the big chips and small chips are relatively smaller as compared to the rake angle $0^{\circ}$. This happens because the chips formation process takes place due to the crushing process and shearing process which takes place alternately.

Tab. 2 SEM image shape of chips powder

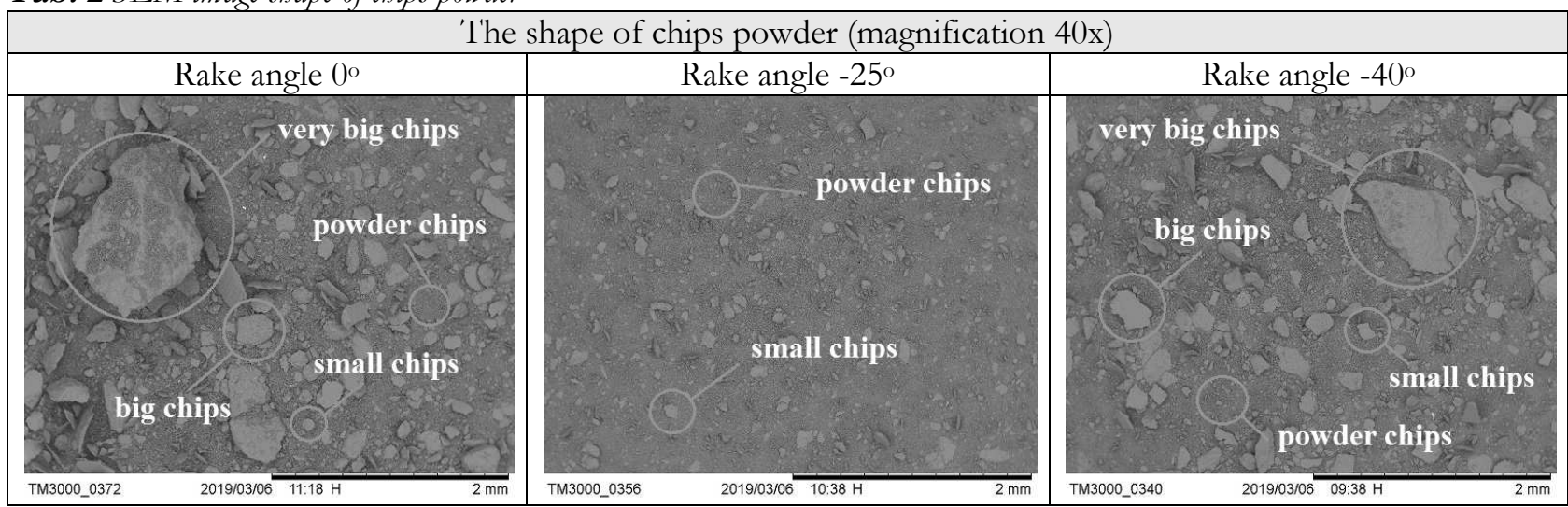

The process of the chips formation was caused by the crushing and shearing mechanism related to brittle failure or crack initiation [11]. The size of chips powder varies during the cutting process owing to the homogeneity of the rock material. Fine chips are formed due to the crushing mechanism, while big chips are formed due to the shearing mechanism. The chips formation phenomenon can be explained by surface energy and crack propagation theory. When the tool interacts with the rock material, the rock gets crushed, and fine powder is formed. This process results from the crushing mechanism. Over a period of time, the surface energy increases due to crack propagation. Finally, big chips formed due to the shearing mecha- nism. After a big chip was formed, a state of rock energy returned to a stable level [2,9]. Hydrostatic pressure changed the cutting mode from brittle cutting mode to the ductile cutting mode [1]. This transformation leads to the size of chips from big size chips, small size chips, and chips powder.

\section{Surface Roughness Measurement Results}

Surface roughness begins from neutral angle $0^{\circ}$, surface roughness values tend to decrease until the minimum value of $1.21 \mu \mathrm{m}$ on the negative rake angle of $-25^{\circ}$, after which the surface roughness value increases again to the negative rake angle of $-40^{\circ}$. Judging from the longitudinal measurements, the smallest surface roughness value is at position 3 , which is the 
measurement position near the chuck. The largest roughness value is at position 1 , the measurement position farthest from the chuck/tip of the workpiece. This condition is also evidenced in the results of the measurement of the force as the start of cutting the force fluctuation is greater than the force fluctuation at the end of the cutting near the chuck. Negative rake angle $-25^{\circ}$ is known to have the smallest surface roughness value because the negative rake angle $-25^{\circ}$ produces the largest radial force of 15.17 newtons, as shown in Fig. 6. At this moment, the rock cutting process occurs, which creates friction between the tool and rock. This process generates the tangential force and radial force at the tool tip. This process was generated by chips powder. The chip particles interact at the tool tip to raise the radial force. The radial force then goes on to press the rock surface. The results of this study are in line with those of Kaitkay [1] and Verhoef [3].

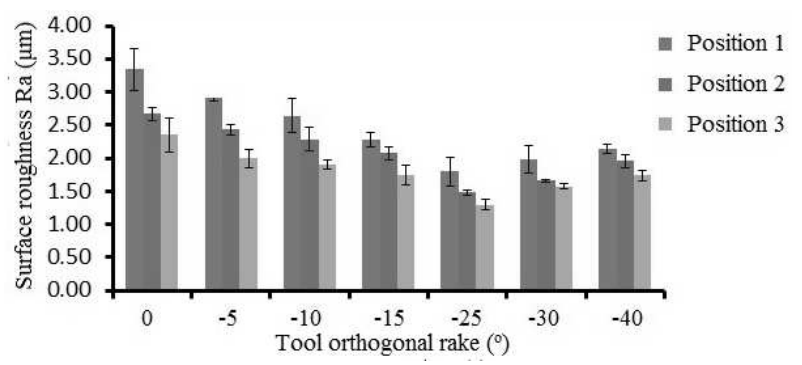

Fig. 6 Average surface roughness with the function of the tool orthogonal rake angle.

Tab. 3 SEM image oriented surface.

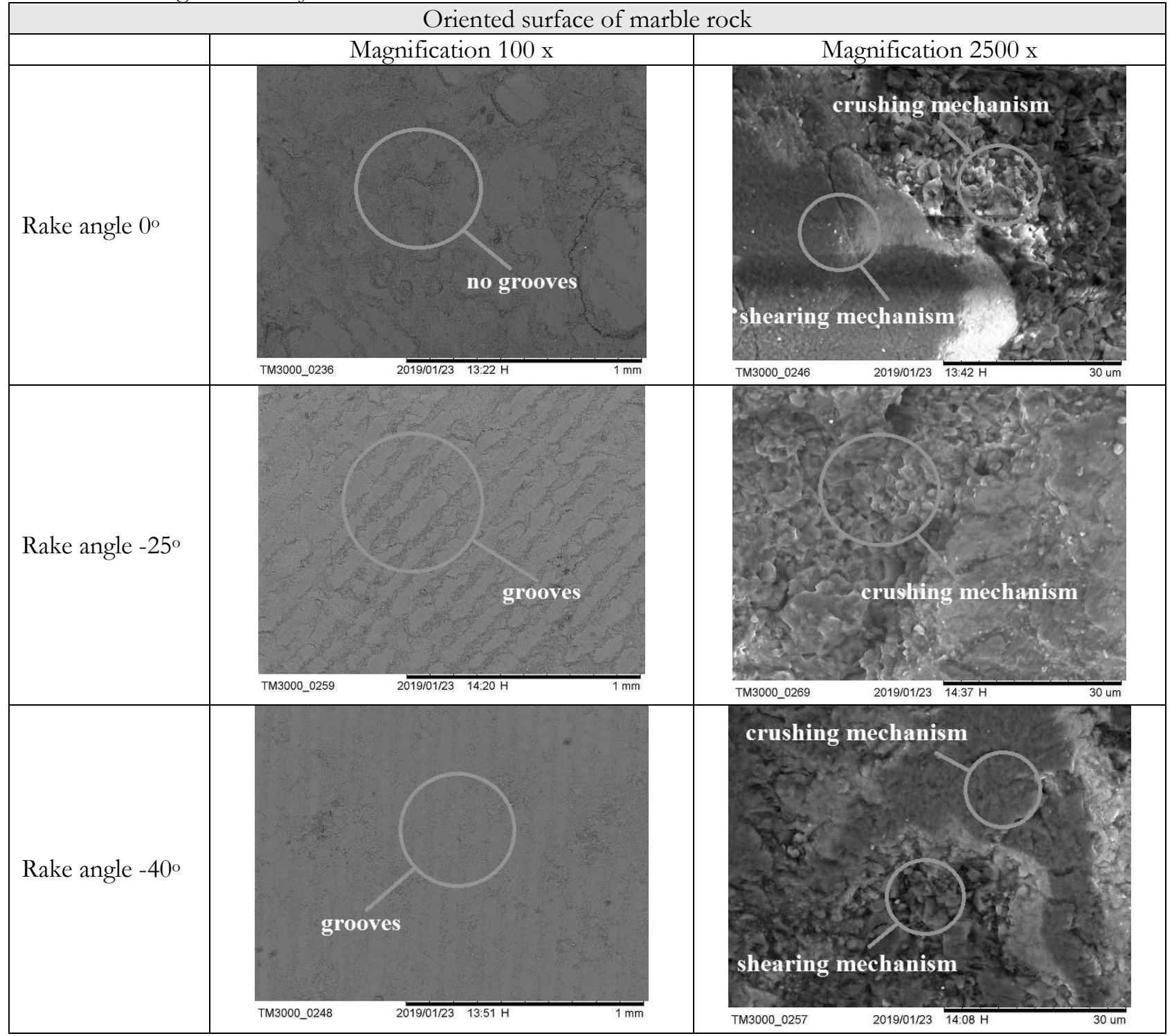

Tab. 3 shows the surface morphology of the marble rock result of the machining process. At rake angle $0^{\circ}$ and 100x magnification, no grooves are yet made by the tool. However, with a 2500x magnification, there is a difference in depth made by the tool. This is because the radial force is very small at rake angle $0^{\circ}$. The radial force is the force that presses the surface of the workpiece. This small radial force leads to the 
dominant brittle cutting mode. In the rock cutting the process of the chips, formation is caused by shearing and crushing mechanism that runs alternately. In this case, the shearing mechanism is more dominant than the crushing mechanism. The shearing mechanism causes cracks to continue to spread, which, in turn, results in a deeper, scratched surface that leads to an uneven surface. In the rake angle of $-25^{\circ}$ and $100 \mathrm{x}$ magnification, it is apparent that there are grooves and former tool pressures. With 2500x magnification, there is a crushing and pressing process from the tool. Almost all workpiece surfaces are known to occur in the crushing mechanism, and the tip of cutting tools made the pressing. This is because the rake angle of $-25^{\circ}$ produces a large radial force. The radial force is the force that presses the surface of the workpiece. This large radial force leads to the dominant ductile-brittle cutting mode. In this case, the crushing mechanism was found to be more dominant than the shearing mechanism $[1,3,9,11]$. The crushing mechanism was pressed on the workpiece uniformly, and no cracks occurred, which resulted in a smooth surface. In the case of rake angle $-40^{\circ}$ with $100 \mathrm{x}$ magnification, it is clear that the grooves are made by the cutting tools. A 2500x magnification entails a combination of shearing, crack, and crushing mechanisms at chips removal. On the surface of the workpiece, there is a former shearing process; crushing and pressing was made by the cutting tool. This is because at a rake angle $-40^{\circ}$ the radial force decreases, so the surface quality declines.

\section{Conclusion}

This research on cutting marble was conducted with the following negative orthogonal rake angles: $0^{\circ}$, $-5^{\circ},-10^{\circ},-15^{\circ},-25^{\circ},-30^{\circ}$ and $-40^{\circ}$. The measurement of cutting force was carried out with a 3 -axial strain gage dynamometer. The following conclusions were reached:

- During the cutting of marble rock, there is force fluctuation of each negative rake angle. These fluctuations indicated a brittle and nonhomogeneous structure of marble rock material. However, stable fluctuations are observed in the negative rake angle of $-25^{\circ}$. This condition demonstrates that the negative rake angle $-25^{\circ}$ occurs on ductile cutting mode as compared to the other negative angle rakes with unstable force fluctuation.

- The hydrostatic pressure changes the cutting mode from brittle to ductile structure. This transformation leads to various forms of chips size. From the results of SEM observations, some forms of chips were found with relative size, namely, very big chips, big chips, small chips and chips powders. The process of chips formation occurs because of the mechanism of crushing, shearing, as well as a combination of crushing-shearing. The big chips are generated from the shearing mechanism while chips powdered are produced from the crushing mechanism.

- From SEM observation, the presence a grooves and former tool pressing was displayed. The cutting mode significantly determines the amount of surface roughness. The brittle and ductile mode occurs dominantly in the shearing mechanism and crushing mechanism, respectively. The shearing mechanism produces a large surface roughness, while the crushing mechanism produces a small surface roughness. The magnitude of the radial force strongly influences this process. The radial force generates a hydrostatic pressure around of the tooltip and continues to press the surface to prevent the initial occurrence of cracks.

\section{Acknowledgement}

The author would like to thanks DRPM - DIKTI for the research funding of the year 2017 Dissertation Doctoral Research Grant, No. Contract: 0556 /UN25.3.1 / LT2017 so that this research can be carried out properly.

\section{References}

[1] KAITKAY, P., LEI, S. (2004), Experimental study of rock cutting under external hydrostatic pressure. Journal of Materials Processing Technology, Vol 159, pp. 206-213.

[2] CHE, D., EHMANN, K.F. (2013). Polycrystalline diamond turning of rock. Proceedings of the ASME, International Manufacturing Science and Engineering Conference MSEC, pp. 1-10.

[3] VERHOEF, P.N.W., OCKELOEN, J.J., KESTEREN, W.G.M.V. (1996). The significance of rock ductility for mechanical rock cutting. Rock Mechanics Journal, pp. 709-716.

[4] CHE, D., HAN, P., GUO, P., EHMANN, K. (2012). Polycrystalline diamond compact cutter-rock interaction from a metal machining point of view part II: bit performance and rock cutting mechanics. Journal of Manufacturing Science and Engineering, Vol. 134, pp. 1-13. 
[5] CHE, D., EHMANN, K. (2014). Experimental study of force responses in polycrystalline diamond face turning of rock. International Journal of Rock Mechanics \& Mining Sciences, Vol 72, pp. 80-91.

[6] GOEL, S., LUO, X., COMLEY, P., REUBEN, R.L. (2013). Brittle-ductile transition during diamond turning of single crystal silicon carbide. International Journal of Machine Tools \& Manufacture, Vol. 65, pp. 15-21.

[7] OZTURK, S. (2012). Slip-line modeling of machining and determine the influence of rake angle on the cutting force. Transactions of the Canadian Society for Mechanical Engineering, Vol. 36, No. 1, pp. 23-35.

[8] WILSON, C., VORONO. (2003). Diamond Turning of Granite", Key Engineering Materials, Vol 250, pp. 138-146.

[9] CHE, D., ZHANG, W., EHMANN, K. (2017). Chip formation and force responses in linear rock cutting: an experimental study. Journal of Manufacturing Science and Engineering, Vol. 139, pp. 1-12.

[10] APPL, F.C., WILSON, C.C., LAKSHMAN, I. (1993). Measurement rock cutting of forces, temperatures, and wear of PDC cutters in rock cutting. Wear, Vol. 169, pp. 9-24

[11] NISHIMATSU, Y. (1972). The mechanic of rock cutting. International Journal of rock mechanic, Vol. 9, pp. 261-270.

[12] CHECKINA, O.G., GHORYACHEVA, I.G., KRASNIK, V.G. (1995). The model for tool wear in rock cutting. Wear, Vol. 198, pp. 33-38.

[13] HOUGH. (1986). The effect of back rake angle on the performance of small-diameter polycrystalline diamond rock bits: ANOVA Tests. Journal of Energy Resources Technology, Vol. 108, pp. 305-309.
[14] HAMADE, R.F., MANTHRI, S.P., PUSAVEC, F., ZACNY, K.A., JAWAHIR, I.S. (2010). Compact core drilling in basalt rock using PCD tool inserts: Wear characteristics and cutting forces. Journal of Materials Processing Technology, Vol. 210, pp. 1326-1339.

[15] CHE, D., PENG, B., HAN, P., EHMANN, K.F. (2014). Finite element study on chip formation and force response in two dimensional orthogonal cutting of rock. Proceedings of the ASME 2014 International Manufacturing Science and Engineering Conference, pp. 1-10.

[16] PATTEN, J., MCSPADDEN, S., NEMANICH, R. (2003). High-pressure phase transformation of silicon nitride. Applied Physics Letters, Vol. 83, pp. 4740-4742.

[17] MITAL, D., HATALA, M., BERNAT, A., et al. (2018). Dependence of surface roughness on depth of cut for aluminium alloy AlCu4Mg1. Manufacturing Technology, Vol. 18, pp. 285-288.

[18] BOTKO, F., HATALA, M., MITALOVAET, Z., al. (2018). Qualitative evaluation of machined surface of aluminum alloy $\mathrm{AlCu} 4 \mathrm{Mg} 1$ depend on feed rate. Manufacturing Technology, Vol. 18, pp. 201-207.

[19] KUNDRÁK, J., ANGELOS P. MARKOPOULOS, et al. (2018). Analysis of the effect of feed on chip size ratio and cutting forces in face milling for various cutting speeds. Manufacturing Technology, Vol. 18, pp. 431-436.

[20] KIC, P., MÜLLER, M. (2018). Dust concentration in air during the MDF boards and polystyrene milling operations on CNC milling machine. Manufacturing Technology, Vol. 18, pp. 923927. 